\title{
ABORDAGEM DO BIOMA CERRADO EM LIVROS DIDÁTICOS DE BIOLOGIA DO ENSINO MÉDIO
}

\author{
R. G. BEZERRA ${ }^{1}$ e R. C. SUESS ${ }^{2}$ \\ ${ }^{1}$ Instituto Federal de Educação, Ciência e Tecnologia de Goiás - Campus Formosa e bolsista do PIBID CAPES/IFG \\ ${ }^{2}$ Universidade Estadual de Goiás - Unidade Universitária de Formosa \\ ra.fagonalves@hotmail.com - rodrigo.capellesuess@gmail.com
}

Artigo submetido em fevereiro/2013 e aceito em março/2013

\section{RESUMO}

A educação brasileira tem os livros didáticos como principal recurso de informação a alunos e professores. Este trabalho analisa como ocorre a abordagem do bioma Cerrado em seis livros didáticos de biologia destinados ao Ensino Médio. Os aspectos analisados foram o número de páginas destinadas ao tema, figuras, exemplificações acerca da fauna e flora local e abordagem do tema. A análise mostrou que todos os aspectos são apresentados de maneira resumida. Exemplos da fauna e flora local, quando presente nos livros, são citados apenas com o nome popular. Como resultado, o bioma Cerrado é tratado de maneira acrítica quanto à sua situação de degradação e importância para a manutenção da biodiversidade mundial.

PALAVRAS-CHAVE: Ensino de Biologia, Cerrado, livros didáticos.

\section{CERRADO BIOME APPROACH IN TEXTBOOKS OF BIOLOGY HIGH SCHOOL}

\section{ABSTRACT}

Brazilian education has the textbooks as the main information resource for students and teachers. This work analyzes how occurs the approach about the Cerrado biome in six biology textbooks for the high school. The aspects analyzed were the number of pages for the topic, figures, exemplifications about the local fauna and flora and approach of the subject. The analysis showed that all aspects are briefly presented. Examples of local fauna and flora, when present in the books, are mentioned only with the popular name. As a result, the Cerrado is treated uncritically as their state of degradation and importance to the maintenance of global biodiversity.

KEY-WORDS: Biology teaching, Cerrado, textbooks. 
ABORDAGEM DO BIOMA CERRADO EM LIVROS DIDÁTICOS DE BIOLOGIA DO ENSINO MÉDIO

\section{INTRODUÇÃO}

A educação brasileira tem os livros didáticos como principal recurso de informação a alunos e professores. Para Gérard e Roegiers (1998), o professor utiliza o livro didático (LD) na tentativa de adquirir informações científicas, enquanto os alunos o utilizam para a obtenção de aprendizagens escolares para a vida cotidiana ou a vida profissional.

O livro didático pode ser definido, conforme Stray, como um produto cultural composto, híbrido, que se encontra no "cruzamento da cultura, da pedagogia, da produção editorial e da sociedade" (1993, p. 77-78). Ele está presente no sistema educacional desde os primeiros anos de alfabetização de uma criança até os últimos anos de sua formação universitária (XAVIER \& SOUZA, 2008).

De acordo com Franco (1992), a implantação do livro didático nas escolas foi oficializada em 1938, portanto, há mais de setenta anos. A partir do ano de 2005, mediante o Programa Nacional do Livro Didático (PNLD), tal prática foi adotada também no Ensino Médio e agora "vivese um momento em que o Programa Nacional do Livro Didático abrange todas as disciplinas do Ensino Médio, fato que se constitui em um aspecto importante no fortalecimento dessa etapa da Educação Básica" (PNDL, 2012, p. 7).

O LD, teoricamente, tem como função auxiliar o professor no desenvolvimento de atividades pedagógicas. Entretanto, dadas às condições enfrentadas pela educação pública brasileira, o LD serve como meio de subsídio a professores no planejamento de suas aulas e um meio de apresentar e discutir conhecimentos científicos aos discentes. O LD, como recurso didático, exerce certa influência na organização do trabalho pedagógico, seja de forma direta, quando adotado pela escola ou professor, ou de maneira indireta, como material de apoio (XAVIER \& SOUZA, 2008).

Essa limitação faz com que o conhecimento seja reduzido ao que o LD apresenta e às suas sugestões de atividades. Conforme argumentam Vasconcelos e Souto (2003), as consequências destes problemas agravam-se ao considerarmos que uma parcela considerável de professores ainda concebe os livros didáticos como inflexíveis manuais norteadores dos programas.

Souza (1995) explica que, para os professores, o LD representa o conhecimento que deve ser aprendido, e por estar hierarquicamente organizado, "demonstra passo a passo" como o ensino deve ser processado. Assim, é utilizado pelos professores na escolha de conteúdos e a metodologia a ser seguida em sala de aula, valorizando um ensino informativo e teórico (KRASILCHIK, 2004).

O que não deve ser negado é que em muitas escolas o LD é o único recurso disponível a professores e alunos para discussões ou tarefas tanto em sala de aula como nas atividades extraclasse, tornando-se a pedra fundamental no processo de formação dos alunos (VASCONCELOS E SOUTO, 2003) devendo, então, ser objeto de constante pesquisa na qualidade de seu serviço à educação.

No Ensino Médio, o estudo dos biomas e ecossistemas brasileiros insere-se no conteúdo programático da disciplina de Biologia. Por isso, espera-se que os LDs de biologia do Ensino 
Médio tratem do assunto, pois o Brasil é considerado um dos países de maior diversidade por abrigar cerca de $10 \%$ dos seres vivos do planeta (MYERS et al., 2000) e os seus biomas caracterizam-se por apresentar grande endemismo, diversidade biológica e um rico patrimônio genético. Além disso, a diversidade ecossistêmica presentes no território nacional possui grande relevância mundial (ASSUNÇÃO \& FELFILI, 2004).

Dentre os biomas brasileiros, o Cerrado teve sua cobertura vegetal significativamente reduzida nos últimos 50 anos. 0 conhecimento da biodiversidade sustentada por esse bioma e sua rápida diminuição pode instigar os estudantes a assumir um posicionamento crítico frente às transformações negativas que seres humanos vêm promovendo e, assim, propor ações na tentativa de sua preservação a fim de melhorar a qualidade de vida.

Segundo os Parâmetros Curriculares Nacionais do Ensino Médio (PCNEM) (BRASIL, 1999), é essencial que o ensino de biologia propicie ao aluno lidar com informações, elaborá-las, refutálas, quando pertinente, e compreender questões afins como ocupação humana e degradação ambiental. Isso só pode acontecer por meio da educação e sabe-se que para o seu desenvolvimento um dos recursos utilizados é o LD.

Sendo assim, considerando o tema bioma Cerrado e a importância do LD no processo de ensino e aprendizagem, este trabalho tem como objetivo analisar como o bioma Cerrado é abordado em seis livros didáticos de Biologia do Ensino Médio. Tal análise se mostra relevante uma vez que o conhecimento do Cerrado é imprescindível na tentativa de preservar e recuperar este bioma e o LD se mostra como fonte de estudo alunos e professores contribuindo, dessa forma, para a aprendizagem sobre o Cerrado.

\section{O BIOMA CERRADO}

O bioma Cerrado abrange cerca de 2 milhões de $\mathrm{km}^{2}$, equivalente a quase um quarto do território nacional (RIBEIRO \& WALTER, 2008) sendo, portanto, a segunda maior formação vegetal brasileira e também a savana tropical mais rica e ameaçada do planeta. Esse bioma abrange o Planalto Central brasileiro, cobrindo o Distrito Federal e grande parte dos estados de Mato Grosso, Mato Grosso do Sul, Tocantins, Goiás, Minas Gerais, Maranhão, Piauí, e partes dos estados de São Paulo, Bahia, Para, Paraná, Sergipe, Roraima, podendo ainda ocorrer em partes dos estados do Amazonas, Amapá e Rondônia (RIBEIRO \& WALTER, 2008).

Concentra cerca de um terço da biodiversidade brasileira (ALHO \& MARTINS, 1995) e nada menos do que $5 \%$ da diversidade da fauna e flora mundiais (KLINK et al.,1995). A riqueza florística do bioma inclui mais de 12 mil espécies (MENDONÇA et al., 2008), sendo 4,4 mil endêmicas, e a fauna engloba cerca de 1200 espécies de vertebrados (MYERS et al. 2000).

O Cerrado abriga uma diversidade muito ameaçada e ainda pouco conhecida. A degradação que ele vem sofrendo nos últimos 50 anos, devido à instalação de represas para geração de energia elétrica, à constante fragmentação para dar lugar ao rápido avanço de plantios de monoculturas e pastagens, além o crescimento desordenado das cidades.

Cerca de $7,44 \%$ da cobertura do bioma Cerrado são protegidos por unidades de conservação, federais, estaduais e municipais, sendo que aproximadamente 2,91\% do Cerrado é protegido na forma de unidades de conservação de proteção integral, tais como os parques nacionais (MMA/IBAMA, PNUD, 2009). 
Alguns estudos, como os de Mittermeier et al. (2000) e Myers et al. (2000), apontam que os remanescentes do bioma correspondem à apenas $20 \%$ da sua cobertura original. Por isso, 0 Cerrado é considerado um dos 25 "hotspots" da Terra, devido ao endemismo de espécies e ao grau de ameaça a que está submetido (MYERS et al., 2000; SILVA \& BATES 2002).

Bizerril (2001) argumenta que a imagem popularmente construída do Cerrado é a de um ambiente pobre em espécies animais e vegetais, caracterizado pela escassez de água e de nutrientes do solo e pela presença de plantas tortuosas e secas em razão das queimadas frequentes. Essas informações estereotipadas do bioma são divulgadas até em livros didáticos, contribuindo para a desvinculação de sua realidade como que abriga vários cenários de belezas naturais e uma diversidade única. Portanto, uma análise detida sobre o tema Cerrado em LDs se faz necessária, pois o seu conhecimento não pode se limitar a sua descrição física e a imagem de um ambiente que abriga árvores tortuosas é sinal de baixa diversidade.

\section{METODOLOGIA}

Esta pesquisa foi desenvolvida no âmbito do Programa Institucional de Bolsas de Iniciação à Docência (PIBID) do Instituto Federal de Goiás (IFG), desenvolvido em um colégio público da cidade de Formosa, Goiás. A organização do estudo se deu com base nos pressupostos da pesquisa qualitativa e qualitativa. De acordo com Bogdan e Biklen (2006), as principais características de uma pesquisa qualitativa são: descrição; interesse pelo processo e não apenas pelo resultado da pesquisa; ter o pesquisador como instrumento chave para o desenvolvimento do trabalho; questionamento do objeto de investigação e análise indutiva dos dados (os dados estabelecem a direção da pesquisa).

No presente trabalho, analisou-se como se dá a abordagem do bioma Cerrado em seis LDs de Biologia que constavam no acervo da biblioteca do colégio onde o PIBID é desenvolvido e estão descritos no Quadro 1.

Quadro 1 - Relação de livros didáticos analisados.

\begin{tabular}{|c|c|c|c|c|c|}
\hline Livro & Autor & Editora & Volume & Ano & Código \\
\hline Biologia Hoje & Gewandsnajder \& Linhares & Ática & 03 & 2010 & LD 1 \\
\hline Biologia & Paulino & Ática & 03 & 2005 & LD 2 \\
\hline Biologia & Silva Júnior \& Sasson & Saraiva & 03 & 2005 & LD 3 \\
\hline Biologia & Uzunian \& Birner & Harbra & 03 & 2005 & LD 4 \\
\hline Biologia & Laurence & $\begin{array}{c}\text { Nova } \\
\text { Geração }\end{array}$ & Único & 2005 & LD 5 \\
\hline Bio & Lopes & Saraiva & Único & 2008 & LD 6 \\
\hline
\end{tabular}

Todos os livros citados forma analisados seguindo os mesmo procedimentos e utilizandose os mesmos critérios. Foram analisados os seguintes pontos nos LDs: 1) Número de páginas dedicadas ao conteúdo; 2) Figuras: i) a que elas se referiam quando apresentadas; ii) clareza e coerência com o texto; iii) quantidade; 3) Fauna e a flora do Cerrado: i) número de exemplos; ii) se acompanha o nome científico e/ou popular; 4) Conteúdo referente aos seguintes tópicos: $i$ ) clima; ii) solo; iii) fogo; iv) biodiversidade; v) degradação ambiental.

A apreciação do número de páginas destinadas ao tema Cerrado nos LDs considerou as páginas destinadas ao conteúdo, inclusive figuras, textos-boxes, exercícios e leitura complementar, excluindo-se as do glossário, gabaritos e bibliografia. Os dados coletados foram analisados e agrupados em planilhas, assim como na forma de gráficos para uma melhor 
visualização dos resultados. Foram utilizados gráficos que mostrassem, de forma clara, a distribuição e as tendências dos dados, facilitando o entendimento da análise.

\section{RESULTADOS E DISCUSSÃO}

Ao todo foram analisados seis livros didáticos que estavam disponíveis no acervo da biblioteca do colégio onde o PIBID de Biologia do IFG, Campus Formosa, é desenvolvido. Em geral, o tema Cerrado é discutido em capítulos referentes a biomas e domínios fitogeográficos do Brasil.

Segundo Carlini-Cotrim \& Rosemberg (1991), a importância que é dada a determinado assunto em um livro didático pode ser medida, por exemplo, pelo número de páginas que o autor dedica a ele. Isso reflete diretamente na aprendizagem dos alunos na medida em que os professores utilizam o LD para preparar as aulas e os discentes o utilizam como material de consulta. A Figura 1 mostra o número de páginas que cada autor destinou ao tema Cerrado.

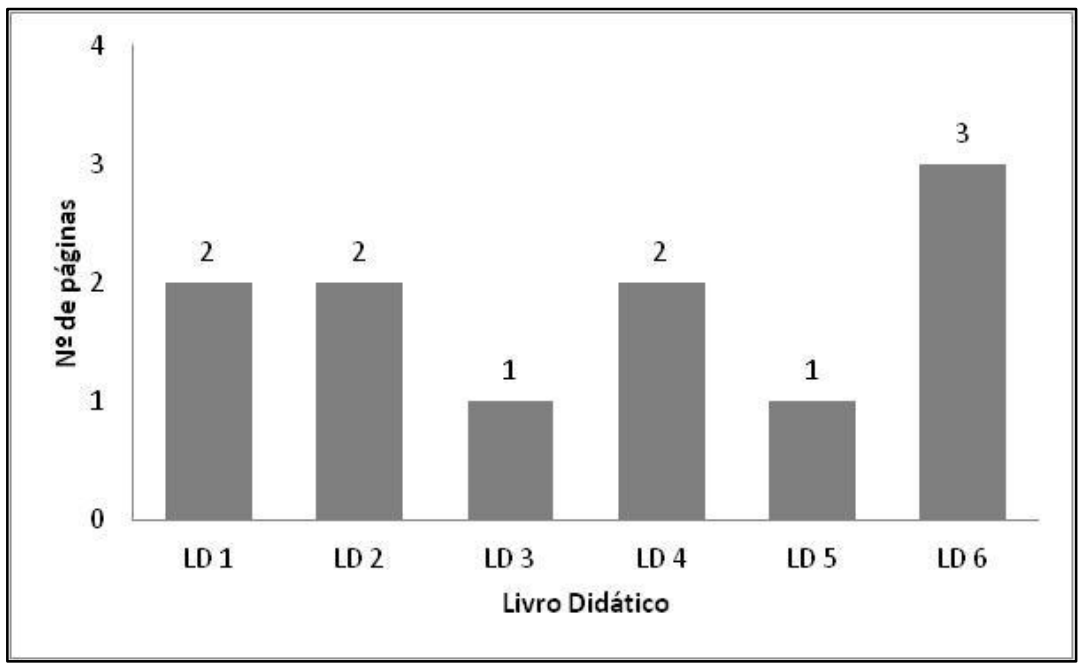

Figura 1 - Número de páginas dedicadas ao tema Cerrado em seis livros didáticos (LD) de Biologia.

Conforme a Figura 1 mostra, a quantidade de páginas destinadas ao tema Cerrado nos LDs analisados é reduzida. Ou seja, menos de 2 páginas por livro, em média. A quantidade de páginas está aquém de tratar do assunto que envolve um bioma tão representativo. Assim, por deter uma enorme biodiversidade, concentrar grande parte da atividade agropecuária brasileira e sofrer incalculável devastação ambiental esse tema deveria ser apresentado de maneira mais detida em LDs.

A Figura 2 retrata a o número de imagens apresentadas nos LDs acerca do bioma Cerrado. O LD 1 mostra uma figura, que trata da vegetação do Cerrado e de espécies pertencentes à fauna local - ema, seriema, lobo-guará e tamanduá-bandeira - com a devida citação da figura no texto. O LD 2 apresenta uma figura que representa o cerrado senso restrito. O LD 3 apresenta uma figura, sem citação no texto, que trata da vegetação do Cerrado. O LD 4 apresenta uma figura que trata da paisagem do Cerrado sem fazer a devida referência no texto. Além disso, há uma referência a "cerrados" na imagem dos LDs 3 e 4, porém o Cerrado é um único bioma, constituído por vários tipos de vegetação (RIBEIRO \& WALTER, 2008). Uma figura é apresentada no LD 6, sem citação no texto, apontando para a vegetação do Cerrado. 


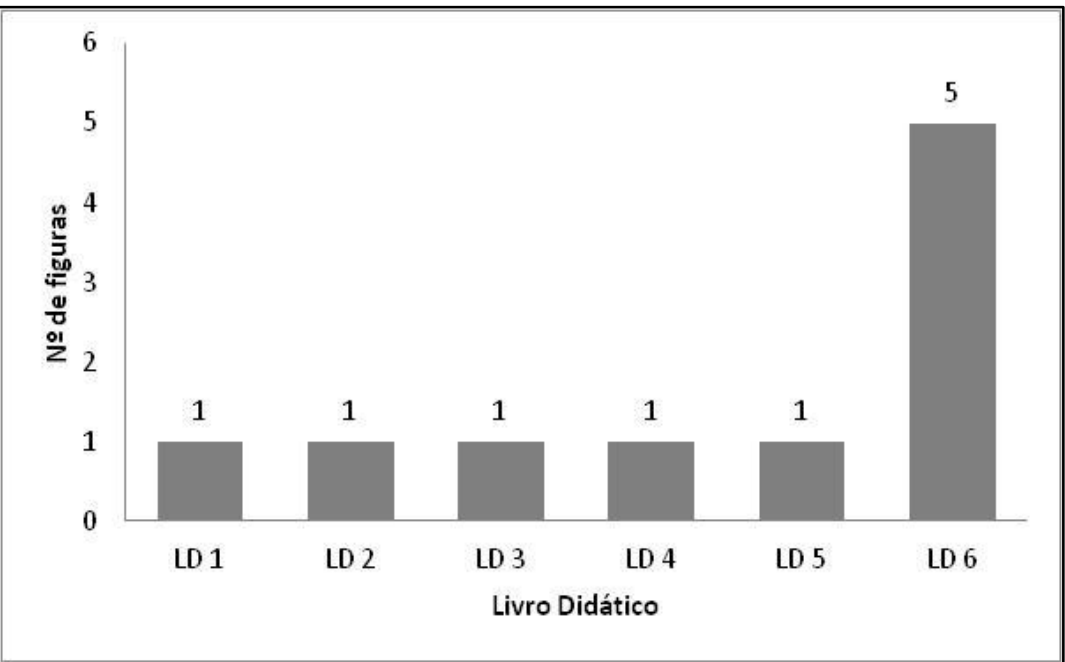

Figura 2 - Número de figuras dedicadas ao bioma Cerrado nos livros didáticos (LDs) analisados.

O LD 6 dispôs do maior número de figuras, 5, cuja referência não é citada pelo texto principal, e uma das imagens não está clara o suficiente para que o aluno compreenda o que é um xilopódio. De acordo Vasconcelos \& Souto (2003), os livros didáticos deveriam tornar as informações mais claras, estimulando a compreensão por parte dos leitores dos textos científicos. Assim, a elaboração de imagens, ilustrações, etc. deve primar pela clareza das informações a fim de promover uma aprendizagem significativa.

A importância das imagens nos livros didáticos está no fornecimento de subsídios para uma melhor compreensão e avaliação da natureza das demandas desse texto (MARTINS; GOUVÊA, 2005). No ensino/aprendizagem de Biologia, a utilização de imagens é imprescindível, porém ilustrações sem a devida explicação e referência no texto tendem a confundir o aluno. Como explica Carneiro (1997), os livros geralmente tendem a supervalorizar as figuras, entretanto, mesmo que as imagens constituam um bom recurso para facilitar a aprendizagem dos conhecimentos, estas por vezes aparecem apresentando um caráter científico e devem estar relacionadas com o texto escrito e a temática abordada.

Em todos os LDs analisados, a vegetação do Cerrado foi exemplificada com figuras que ilustrassem árvores com tronco tortuoso, sem haver referências às formações florestais que este bioma possui: cerradão, mata seca, mata de galeria e mata ciliar. Segundo o LD 1, no Cerrado "os caules das árvores são tortuosos (...) os troncos são recurvados e torcidos (p. 312). As figuras tratavam do que se chama Cerrado sentido restrito (RIBEIRO \& WALTER, 2008), mas não explicavam sobre isso.

Foi, também, observada uma predominância, nos livros analisados, de exemplos de flora e fauna do Cerrado na forma de texto, inclusive a sua utilização em ilustrações. O Quadro 2 mostra os exemplos de espécies da flora e fauna do Cerrado citados nos LDs e também se há a ocorrência de nome popular e/ou científico. 
Quadro 2. Exemplos da flora e fauna do Cerrado citados nos livros didáticos (LD) com respectivo emprego de nome popular e/ou científico.

\begin{tabular}{|c|c|c|c|c|c|c|}
\hline \multicolumn{4}{|c|}{ Flora } & \multicolumn{3}{|l|}{ Fauna } \\
\hline $\begin{array}{l}\text { Livro } \\
\text { didático } \\
\text { (LD) }\end{array}$ & Exemplos & $\begin{array}{c}\text { Nome } \\
\text { popular }\end{array}$ & $\begin{array}{c}\text { Nome } \\
\text { científico }\end{array}$ & Exemplos & $\begin{array}{c}\text { Nome } \\
\text { popular }\end{array}$ & $\begin{array}{c}\text { Nome } \\
\text { científico }\end{array}$ \\
\hline LD 1 & $\begin{array}{l}\text { Barbatimão, pau-santo, } \\
\text { araçá, pau-terra, } \\
\text { catuaba, indaiá, } \\
\text { gonçalo-alves, sucupira, } \\
\text { gariroba, angico, } \\
\text { caviúna, ipê-do-cerrado, } \\
\text { peroba-do-campo, } \\
\text { pequizeiro, capim- } \\
\text { flecha, capim-barba-de- } \\
\text { bode, cajueiro-do- } \\
\text { cerrado, mangaba, } \\
\text { jatobá, murici }\end{array}$ & Sim & Não & $\begin{array}{l}\text { Tamanduá-bandeira, tatu- } \\
\text { canastra, quati, macaco-prego, } \\
\text { o sagui, rato-do-mato, anta, } \\
\text { capivara, porco-do-mato, } \\
\text { veado-campeiro, onça-pintada, } \\
\text { suçuarana, jaguatirica, lobo- } \\
\text { guará, cachorro-vinagre, furão, } \\
\text { cangabá, guaxinim, seriema, } \\
\text { gralha, asa-branca, papagaio, } \\
\text { araraúna, tucano, a coruja, pica- } \\
\text { pau, socó, ema, gavião-preto, } \\
\text { gavião-carcará, urubu-rei, } \\
\text { jararaca, cascavel, jiboia, sucuri, } \\
\text { cágado, jabuti. }\end{array}$ & Sim & Não \\
\hline LD 2 & $\begin{array}{l}\text { Lixeira, pau-terra, } \\
\text { sucupira, pequi, } \\
\text { copaíba, angico, } \\
\text { caviúna, barbatimão } \\
\text { capim-barba-de-bode }\end{array}$ & Sim & Não & $\begin{array}{l}\text { Veado-campeiro, raposa-do- } \\
\text { campo, lobo-guará, tamanduá- } \\
\text { bandeira, tatu-canastra, gavião- } \\
\text { preto e o sabiá-do-campo }\end{array}$ & Sim & Não \\
\hline LD 3 & Ipê & Sim & Não & - & - & - \\
\hline LD 4 & $\begin{array}{c}\text { Araticum, barbatimão, } \\
\text { copaíba, ipê-amarelo, } \\
\text { pequizeiro, pau-terra, } \\
\text { fruta-de-lobo, cajueiro- } \\
\text { do-cerrado, lobeira, } \\
\text { gabiroba, araçá }\end{array}$ & Sim & Não & Lobo-guará & Sim & Não \\
\hline LD 5 & $\begin{array}{l}\text { Araçá, murici, indaiá, } \\
\text { gabiroba, pau-terra, } \\
\text { capim-flecha }\end{array}$ & Sim & Não & $\begin{array}{c}\text { Ema, seriema, tamanduá- } \\
\text { bandeira, veado-campeiro, } \\
\text { lobo-guará }\end{array}$ & Sim & Não \\
\hline LD 6 & $\begin{array}{c}\text { Araçá, murici, gabiroba, } \\
\text { pau-terra, indaiá e } \\
\text { capim-flecha }\end{array}$ & Sim & Não & $\begin{array}{l}\text { Ema, lobo-guará, onça pintada, } \\
\text { anta, tamanduá, tatu e veado- } \\
\text { campeiro }\end{array}$ & Sim & Não \\
\hline
\end{tabular}

A flora e fauna do bioma Cerrado foram citadas através de exemplos que envolvessem apenas os nomes populares das espécies ocorrentes no local. O LD 3 não cita nenhuma espécie da fauna e apenas o Ipê como exemplo da flora local. Tal fato, aliado a falta de referência dos nomes científicos das espécies, contribui para o uma formação deficiente acerca do bioma Cerrado na medida em que uma espécie pode receber o nome popular de acordo com cada região, como pode ser notado com os nomes fruta-de-lobo e lobeira pertencentes à espécie Solanum lycocarpum A.St.-Hil. (Solanaceae). Assim, para atrelar conhecimento de senso comum com o conhecimento científico seria necessário que os livros trouxessem os nomes populares da flora e fauna acompanhados dos seus respectivos nomes científicos.

Todos os livros analisados apresentam tópicos referentes à localização geográfica e abrangência do Cerrado, cerca de um quarto do território nacional. Entretanto, foi possível notar que não há consenso no que diz respeito aos estados onde o bioma ocorre, sendo predominantes as informações relacionadas ao Planalto Central brasileiro. Porém, o bioma abrange estados das regiões Sul, Sudeste, Centro-Oeste, Nordeste e Norte. 
Embora a intenção de priorizar na elaboração de livros didáticos um conteúdo simples, não significa que ele deverá ser pobre. Pelo contrário, significa que ele deverá ser claro, objetivo e acessível. Infelizmente, parece que isso é confundido. Deve-se rumar para construção de conteúdos com linguagem simples, porém coesa e rica em informações de maneira a possibilitar um melhor processo de ensino-aprendizagem dirigido e auxiliado pelo professor e voltado para os discentes.

Exceto o LD 4, que não cita as características climáticas do bioma, os demais livros explicam que o Cerrado apresenta uma estação seca e outra chuvosa, porém há confusão com relação à classificação climática: semiúmido tropical (LD 2) e clima quente (LDs 1, 3, 5 e 6) foram citados.

O tópico referente aos solos do bioma evidencia a composição das características químicas ao dizer que são "ácidos, ricos em alumínio e pobre em nutrientes como causas do baixo crescimento das plantas" (LD 1). Os livros citam também sobre a agricultura, a profundidade do solo e o desenvolvimento das raízes das plantas para a obtenção de água. Conforme Reatto et al. (2008), há grande correlação entre a vegetação e o solo no Cerrado e sua compreensão é fundamental para o estudo do comportamento do meio ambiente, por isso, fazse necessário a abordagem desse assunto.

O tipo de vegetação apresentado pelo Cerrado associa-se a diferentes classes de solos e formações geológicas que, somados a condição climática, são capazes de gerar diferenças entre as comunidades vegetais (COSTA \& OLSEVSKI, 2008). Adicione-se a isso a influência da latitude, a frequência das queimadas, a profundidade do lençol freático e os inúmeros fatores antrópicos (RIBEIRO \& WALTER, 2008).

A importância do fogo natural para o Cerrado é abordada de maneira superficial, exceto no LD 6 que trata mais detidamente sobre o assunto. Também foram citadas as adaptações das plantas para enfrentar o fogo, como cascas espessas ou caules subterrâneos (LDs 1, 2, 3, 5 e 6). 0 LD 4 que não explica a importância do fogo para o bioma.

A biodiversidade é tratada através de exemplos da fauna e da flora em todos os livros. Apenas os LDs 1 e 3 citam a importância das plantas medicinais existentes no bioma. Apenas os LDs 1 e 6 referem-se sobre a importância da preservação do Cerrado, criação de unidades de conservação e da degradação que ele vem sofrendo através de atividades agrícolas, caça, extração de madeira.

\section{CONSIDERAÇÕES FINAIS}

Após analisar o tema Cerrado em seis livros didáticos de Biologia do Ensino Médio, percebemos que de fato o bioma Cerrado é tratado de maneira acrítica quanto à sua situação de degradação e importância para a manutenção da biodiversidade mundial. Todas as figuras dos livros mostravam vegetação típica do cerrado sentido restrito com árvores tortuosas, sem explicações de que o bioma possui formações campestres, savânicas e florestais, o que contribui para estereotipização do bioma Cerrado, contribuindo para uma visão de um ambiente improdutivo biologicamente e pouco diverso. O conteúdo é tratado em cada livro de maneira bem resumida, não levando em consideração a real importância do bioma Cerrado para a manutenção da vida no Planeta Terra. 
Dessa forma, levando-se em consideração que o livro didático ainda é o principal recurso utilizado por professores e alunos no ensino-aprendizagem, sugere-se a abordagem do tema Cerrado em livros didáticos ocorra de maneira organizada, com exemplos da fauna e da flora acompanhados dos respectivos nomes populares e científico. Ressalta-se, a importância da utilização de publicações desde científicas a artigos de jornais, revistas e sites, além de programas televisionados do cotidiano dos estudantes, aproximando-o ainda mais do conteúdo do seu dia-a-dia.

Além disso, este trabalho foi capaz detectar que, nos livros didáticos analisados, o conteúdo sobre o Cerrado necessita ser complementado pelos professores. Ressalta-se, a importância da utilização de publicações desde científicas a artigos de jornais, revistas e sites, além de programas televisionados do cotidiano dos alunos, assim aproximando-o ainda mais do conteúdo do seu dia-a-dia.

Sendo assim, todos os livros analisados podem ser melhorados e adequados para uma educação voltada para a cidadania, com base em conteúdos e atividades que levem à reflexão de alunos e professores sobre a enorme importância e rica biodiversidade que o Cerrado tem.

\section{REFERÊNCIAS BIBLIOGRÁFICAS}

1. ALHO, C. J. R. \& MARTINS, E. S. De Grão em Grão, o Cerrado Perde Espaço (Cerrado Impactos do Processo de Ocupação). WWF- Fundo Mundial para a Natureza. Brasília, 1995.

2. ASSUNÇÃO, S. L.; FELFILI, J. M. Fitossociologia de um fragmento de cerrado sensu stricto na APA do Paranoá, DF, Brasil. Acta Botanica Brasilica, v.18, n.4, p. 903-909, 2004.

3. BIZERRIL, M. X. A. O Cerrado nos livros didáticos de geografia e ciências. Ciência Hoje, v. 32, n. 192, p. 56-60, 2003.

4. BOGDAN, R. C.; BIKLEN, S. K. Investigação qualitativa em educação: uma introdução à teoria e aos métodos. Porto: Porto Editora, 2006.

5. BRASIL. Guia de livros didáticos: PNLD 2012: Biologia. - Brasília: Ministério da Educação, Secretaria de Educação Básica, 2011.

6. _ Ministério da Educação. Secretaria de Educação Média e Tecnológica. Parâmetros Curriculares Nacionais: ensino médio. Ciências da natureza, matemática e suas tecnologias. Brasília: MEC/SEMT, 1999.

7. CARLINI-COTRIM, B.; ROSEMBERG, F. Os livros didáticos e o ensino para a saúde: o caso das drogas psicotrópicas. Revista de Saúde Pública, São Paulo, v. 25, n. 4, p. 299-305, 1991.

8. CARNEIRO, S. M. H. As imagens no livro didático. In: ATAS do I Encontro Nacional de Pesquisa em Ensino de Ciências. Águas de Lindóia, São Paulo, 1997, p. 366-373.

9. COSTA, L. M.; OLSEVSKI, N. Caracterização da paisagem do Cerrado. In: FALEIRO, F. G. \& NETO, A. L. de F. (Eds.). Savanas: desafios e estratégias para o equilíbrio entre sociedade, agronegócio e recursos naturais. Planaltina (DF): Embrapa Cerrados, 2008.

10. FRANCO, M. L. P. B. O livro didático e o Estado. ANDE, ano I, n. 5, p. 19-24, 1992.

11. GÉRARD, F. M.; ROEGIERS, X. Conceber e avaliar manuais escolares. Porto: Porto Editora, 1998.

12. GEWANDSNAJDER, F.; LINHARES, S. de V. Biologia Hoje. 1. ed. São Paulo: Ática, 2010. 
13. KLINK, C. A.; MACEDO, R. F.; MUELLER, C. C. 1995. De Grão em Grão, o Cerrado Perde Espaço (Cerrado - Impactos do Processo de Ocupação). WWF - Fundo Mundial para a Natureza. Brasília, 1995.

14. KRASILCHIK, Myriam. Prática de ensino de biologia. 4. ed. São Paulo: USP, 2004.

15. LAURENCE, J. Biologia. (Volume único). 1. ed. São Paulo: Nova Geração: 2005.

16. LOPES, S. Bio. (Volume único). São Paulo: Saraiva, 2008.

17. MARTINS, I.; GOUVÊA, G. Analisando aspectos da leitura de imagens em livros didáticos de ciências por estudantes do ensino fundamental no Brasil. Enseñanza de las Ciências. Número extra, VII congresso, p. 1-3, 2005.

18. MENDONÇA, R. C.; FELFILI, J. M.; WALTER, B. M. T.; SILVA JÚNIOR, M. C.; REZENDE, A. V.; FILGUEIRAS, T. S. \& NOGUEIRA, P. E. Flora Vascular do Cerrado. p. 289-556. In: SANO, S. M. \& ALMEIDA, S. P. (eds.). Cerrado: ambiente e flora. Planaltina, DF: EMBRAPA-CPAC, 2008.

19. MITTERMEIER, R. A; MYERS N.; MITTERMEIER C. G. Hotspots: Earth's Biologically Richest and Most Endangered Terrestrial Ecoregions. Mexico City (México): CEMEX, 2000.

20. MMA/IBAMA/PNUD. Relatório técnico de monitoramento do bioma Cerrado, 2002 a 2008: dados revisados. Centro de Informação, Documentação Ambiental e Editoração Luís Eduardo Magalhães - CID Ambiental. Brasília: DF, 2009.

21. MYERS, N.; MITTERMEYER, R. A.; MITTERMEYER, C. G.; FONSECA, G. A.; KENT, J. Biodiversity hotspots for conservation priorities. Nature, v. 403, p. 853-858, 2000.

22. PAULINO, W. R. Biologia. (Volume 3). São Paulo: Ática, 2005.

23. REATTO, A.; CORREIA, J. R.; SPERA, S. T. MARTINS, E. de S. Solos do bioma Cerrado: aspectos pedológicos. In: SANO, S. M. \& ALMEIDA, S. P. (Eds.). Cerrado: ambiente e flora. Planaltina, DF: EMBRAPA-CPAC, 2008.

24. RIBEIRO, J. F.; WALTER, B. M. T. As principais fitofisionomias do bioma Cerrado. In: SANO S. M. \& ALMEIDA, S. P. (Eds.). Cerrado: ambiente e flora. Planaltina, DF: EMBRAPA-CPAC, 2008.

25. SILVA JÚNIOR, C.; SASSON, S. Biologia. Volume 3. 7 ed. São Paulo: Saraiva, 2005.

26. SILVA, J. M. C.; BATES, J. M. Biogeographic Patterns and Conservation in the South American Cerrado: A Tropical Savanna Hotspot. BioScience, v. 52 n. 3, p. 225-233, 2002.

27. SOUZA, D. M. E o livro não "anda", professor? In: CORACINI, Maria José (Org.) 0 jogo discursivo na aula de leitura: língua materna e língua estrangeira. São Paulo: Pontes, p. 11922, 1995.

28. STRAY, C. Quia Nominor Leo: Vers une sociologie historique du manuel. In: CHOPPIN, Alain (org.) Histoire de l'éducation. $\mathrm{n}^{\circ} 58$ (numéro spécial). Manuels scolaires, États et sociétés. XIXe-XXe siècles, Ed. INRP, 1993.

29. UZUNIAN, A.; BIRNER, E. Biologia. (Volume 3). 3 ed. São Paulo: Harbra, 2005.

30. VASCONCELOS, S. D.; SOUTO, E. O livro didático de Ciências no Ensino Fundamental proposta de critérios para análise do conteúdo zoológico. Ciência \& Educação, v. 9, n. 1, p. 93-104, 2003.

31. XAVIER, R. P.; SOUZA, D. T. O que os pensam sobre o livro didático de inglês? Trab. Ling. Aplic., Campinas, v. 47, n. 1, p. 65-89, Jan./Jun. 2008. 